Javier Arienza Arienza

\title{
DON GUILLÉN DE SAN CLEMENTE, EMBAJADOR HISPANO Y CRONISTA DE LA "LARGA GUERRA" CONTRA LOS TURCOS (1593 - 1606)
}

Don Guillén de San Clemente y de Centelles - Guillem Ramón de Santcliment i de Centelles - (1539-1608), noble catalán natural de Barcelona, hijo de don Pedro Juan de San Clemente (Maestresala del Rey Católico y Señor del castillo de Salzer ${ }^{1}$ ) y de doña Isabel Centelles, nieto paterno de don Guillén y San Clemente y de doña Juana de Estelrich y de la Bastida ${ }^{2}$, fue embajador de España en la corte rudolfina de Praga durante la última parte del siglo XVI y principios del siglo XVII, al servicio de los reyes Felipe II y Felipe III.

San Clemente llegó a Praga el 13 de julio de 1581, cuando aún no ostentaba el título de embajador ${ }^{3}$, para sustituir a su homólogo precedente don Juan de Borja y Castro, y allí residió de forma intermitente hasta el día de su muerte el 3 de septiembre de 1608.

El embajador tenía su residencia oficial de Praga en la calle Kanovnicha, junto a la colina del Hradčany (o barrio del castillo), y muy cerca de la iglesia de Santo Tomás de Malá Strana, un templo de frailes agustinos del siglo XIII, primitivamente gótico (luego restaurado en estilo barroco), al cual estaba íntimamente vinculado ${ }^{4}$. Hacia 1581, el personal de la embajada española se situaba en torno a las setenta u ochenta personas.

La historia del embajador San Clemente es tan instructiva como curiosa. Fue un hombre muy implicado en la vida política de su época, congregando en torno a sí, a un grupo nobles checos de orientación procatólica que él mismo denominaba "la facción española" o partido español. El centro de este partido español - aparte de don Guillén de San Clemente -, lo formaban los clanes checos de Perstejn y Lovkovitz. San Clemente, seguramente menos orgulloso y

\footnotetext{
${ }^{1}$ Guillén de SAN CLEMENTE, Correspondencia inédita de don Guillén de San Clemente, Embajador de Alemania de los Reyes Don Felipe II y III sobre la intervención de España en los sucesos de Polonia y Hungría (1581-1608). Publicada por el Marqués de Ayerbe, Zaragoza, 1892, VII.

${ }^{2}$ Para ver su genealogía completa consultar, Luís de SALAZAR Y CASTRO, Colección Salazar y Castro, Real Academia de la Historia, D-51, f. 21.

3 Bohumil BAĎURA, "Los Borja y el Reino de Bohemia", in: Ibero-Americana

Pragensia, XXXIX, Praha, 2007, 60.

${ }^{4}$ Josef FORBELSKÝ, Los españoles, el Imperio y Bohemia en los Siglos XVI y XVII. Vysehrad, 2006, 15-60.
} 
con más sentido práctico que su predecesor Borja (aunque también menos fino y agudo), observó la vida de la corte de una forma más asequible, lo que le reportó una visión más íntegra de los acontecimientos de los que era testigo 5 .

Al llegar a Praga en 1581, San Clemente era ya un hombre de amplia experiencia y un soldado distinguido. Había luchado en la batalla de Lepanto en 1571, donde, al igual que Cervantes, había sufrido una herida grave ${ }^{6}$. Además, don Guillén había servido al rey de España, sucesivamente, en las revueltas de los moriscos en Andalucía (1569-1570), en los conflictos de Flandes - donde también había ejercido como diplomático -, en Saboya, y finalmente Praga, donde residirá hasta su fallecimiento en 1608. Así pues, cuando San Clemente llegó a Praga con 42 años, tenía ya excelentes referencias para realizar su cometido en la corte del emperador Rodolfo II. El historiador Ivo Kořan no duda en considerarle como un "humanista europeo"

San Clemente era además miembro de la Orden de Santiago. Este organismo, instituido hacia el año 1150 y que en sus orígenes tenía un carácter marcadamente militar, había jugado un importante papel durante la reconquista peninsular. Sin embargo, a partir de la incorporación de su maestrazgo a la corona de los Reyes Católicos en 1494, el título de Caballero de la Orden de Santiago pasó a tener más que nada un carácter puramente honorífico ${ }^{8}$. Don Guillén, fue armado caballero de la Orden de Santiago el 20 de octubre de 1580, en presencia del rey Felipe II, por don Luís Fernández Manrique, marqués de Aguilar y Comendador de Socuéllamos, si bien, el despacho con la Cédula real de su hábito había sido emitido ya el 12 de enero de $1580^{\circ}$.

Los elementos distintivos de esta Orden pueden verse en el retrato anónimo del embajador en la colección Lobkowicz recientemente trasladada a

\footnotetext{
5 Bohdan CHUDOBA, España y el Imperio (1519-1643), Madrid, SARPE, 1986, 159. Existe también edición en inglés. El original checo id., Španělé na Bílé hoře, Praha, 1945.

6 Miguel SALVÁ y Pedro SAINZ DE BARANDA, Colección de documentos inéditos para la historia de España, XXI, Madrid, 1852, 320.

${ }^{7}$ Ivo KOŘAN, "Praski krag humanistów wokól Giordana Bruna", in: Euhemer, XIII, Warszawa, 1969, 82.

${ }^{8}$ Acerca de los orígenes y organización de la Orden de Santiago, pueden servir p. ej., D. RODRÍGUEZ BLANCO, La organización institucional de la Orden de Santiago en la Edad Media, en H.I.D., 12, 1985; G. MARTÍNEZ DÍEZ, La cruz y la espada. Vida cotidiana de las órdenes militares españolas, Barcelona, Plaza y Janés, 2002; W. DEREK, La Orden de Santiago, Madrid, 1965; id., Las Órdenes Militares en la Península durante la Edad Media, Salamanca, 1976.

${ }^{9}$ Luís de SALAZAR Y CASTRO, Los comendadores de la orden de Santiago: Prólogo del Marqués de Ciadoncha, Patronato de la Biblioteca Nacional, Madrid, 1949, 169-170, 253.
} 
Praga desde el castillo checo de Nelahozeves ${ }^{10}$. En cuanto que caballero de la Orden de Santiago, Guillén de San Clemente era Comendador del Horcajo (en sucesión de don Gaspar de Robles) y Comendador de Moratalla (Murcia) en sucesión de don Juan de Ayala, al darle Felipe II en título esta encomienda en Toledo a fecha de 3 de julio de 1596. En un Manuscrito del siglo XVIII ${ }^{11}$ y parcialmente autógrafo del propio don Luís de Salazar y Castro, se recoge una cédula del rey Felipe II a todos los comendadores de la Orden de Santiago poniéndoles en pie de guerra y haciéndoles el llamamiento para que, con las personas y lanzas que les corresponden (unas cuatrocientas cincuenta en total), estén dispuestos para marchar a la guerra. En esta carta se llama a don Guillén a incorporarse con sus huestes, citándole como embajador en Alemania y Comendador de Moratalla.

Las relaciones diplomáticas entre España y la casa de Habsburgo habían empezado a desarrollarse hacia los años 60 del siglo XVI, momento en que por vez primera empiezan a intercambiarse embajadores por una y otra parte. A partir de entonces, la situación política y cultural, así como la vida intelectual del Reino de Bohemia, y en especial la de Praga, estuvo influida notablemente por diplomáticos españoles.

En el año 1578, comenzó a ejercer el cargo de embajador en Praga el humanista español don Juan de Borja y Castro, segundo hijo de San Francisco de Borja. La tarea de don Juan de Borja como diplomático en la corte de Rodolfo II fue amplia y productiva para los intereses de la corona de España ${ }^{12}$.

Su sucesor y protagonista de esta monografía, don Guillén de San Clemente, llegó a Praga en julio de 1581 con la intención de que Borja pudiera instruirle en las tareas concernientes a su puesto. Se sabe que en el momento de partir de Praga con dirección a España, Juan de Borja, aprovechó su despedida con el emperador para llevar consigo a San Clemente a su primera audiencia oficial. El emperador Rodolfo II "le hizo tratamiento de embajador, mandándole a sentar y cubrir". Borja introdujo además a San Clemente cerca los ministros del emperador y le dejó las instrucciones antes de su partida, así como algunos expertos en lenguas necesarios para el desempeño de su cargo ${ }^{13}$.

En rasgos generales y a la vista de sus despachos, la tarea diplomática del embajador San Clemente se centró principalmente en la política centroeuropea, como por ejemplo la necesaria ayuda ante el resurgimiento de las ambiciones turcas en Europa, especialmente desde 1593. Baste decir que durante los

${ }^{10}$ Pavel ŠTĚPÁNEK, y E. BUKOLSKÁ, Retratos españoles en la colección Lobkowitz en Roudnice, Archivo Español de Arte, 46, 1973.

${ }^{11}$ SALAZAR Y CASTRO, op. cit., I-34, fols. 3 v. a 6.

${ }^{12}$ Para conocer a fondo este personaje, ver ante todo, BAĎURA, op. cit., 43-72.

${ }^{13}$ Guillén de SAN CLEMENTE a Felipe II, Praha, 25 de julio de 1581. A.G.S, Sección de Estado. 
últimos meses de su vida, Felipe II incluso llegó a considerar la posibilidad de enviar una expedición desde Italia a los Balcanes para liberar las fronteras del imperio de la presión de los otomanos ${ }^{14}$.

Otras tareas no menos importantes que Guillén de San Clemente habría de negociar con el extravagante Rodolfo $\mathrm{II}^{15}$ fueron, el conflicto de los Países Bajos, la elección polaca que siguió a la muerte de Esteban Báthory en 1586 (la Corte de Madrid apoyó -aunque sin éxito - la candidatura del archiduque Maximiliano), así como sus posibles esponsales con la hija mayor del rey, Isabel Clara Eugenia, pretendiendo con ello buscar un heredero al trono imperial afín a la política católica del rey prudente.

El embajador gozaba de una gran influencia dentro de la corte rudolfina, recibiendo por ello grandes pruebas de afecto, no solo de los principales personajes nacionales e internacionales de la época, sino también de la emperatriz María (mujer de Maximiliano II), de doña Isabel (hija de María y reina de Francia), y de los Archiduques Ernesto, Matías y Maximiliano. Numerosos documentos políticos testifican la calidad de los servicios prestados a la corona de España desde su puesto de embajador ${ }^{16}$.

Sin embargo, y pese a ser consciente de la importancia de su situación estratégica, Praga nunca llegó a gustar mucho al embajador, y sus 21 años de estancia en la capital checa los pasó añorando volver de aquel país frío y lluvioso de herejes a la España soleada y católica. El propio San Clemente cita textualmente, "he pasado la mayoría de mi vida entre renegados, pero sería aún más triste para mí, si supiera que mis huesos van a descansar entre los suyos", reflejando con ello el miedo que tenía de morir en un país potencialmente herético como era la Bohemia de su tiempo. San Clemente, como la mayoría de los embajadores de Felipe II, pidió muchas veces su relevo. Sin embargo, y por una cruel ironía de la suerte, cuando finalmente logró la esperada autorización para regresar a España en 1608, fallece en Praga pocos días antes de partir.

Como se ha señalado anteriormente, la correspondencia oficial (y privada) de don Guillén de San Clemente despachada durante su estancia en la corte de

${ }^{14}$ J.H.ELLIOT, La Europa dividida (1559-1598), Madrid, Crítica, 2005, 368.

${ }^{15}$ Sobre la época de Rodolfo II véase p. ej., R. J. W. EVANS, Rudolf II and his World. A Study in intellectual history, 1575-1612, Oxford, 1973, $2^{\mathrm{a}}$ ed. de 1984; id., The Making of the Habsburg Monarchy 1550-1700, Oxford, 1984; Albrecht LUTTENBERGER y Edel ANDREAS, Imperio y territorios imperiales durante el gobierno de Rodolfo II (1576-1612) y Matías (1612-1619), in: "Studia historica". Historia moderna, 23, 2001, 89-148.

${ }^{16}$ SAN CLEMENTE, op. cit., X-XIII. 
Rodolfo II ${ }^{17}$, nos aporta abundantes y muy valiosas informaciones sobre la política centroeuropea de una época (finales del siglo XVI - principios del siglo $\mathrm{XVII})$, en la que la vieja Europa era constantemente acosada por el Imperio Otomano, y donde la monarquía imperial de los Habsburgo experimentaba importantes luchas internas de poder entre los hermanos Rodolfo y Matías.

A modo de ejemplo, podemos citar algunos pasajes de su labor diplomática en relación con el contexto de la "Larga Guerra" contra los turcos:

El 7 de febrero de 1605, San Clemente escribe una carta dirigida a su rey Felipe III, informando sobre los ataques de los turcos y sobre el peligro que esto conlleva. Además escribe acerca la descomposición (todavía pequeña) del mundo católico en la región. Esta política activa del embajador interesará mucho al emperador, ya que, San Clemente pide ayuda (especialmente de tipo financiera) al rey español, con el fin de que los Habsburgo austriacos pudiesen recuperar de nuevo los territorios ocupados por los turcos otomanos ${ }^{18}$.

El 6 de mayo de 1605, el embajador San Clemente escribe una carta al rey Felipe III sobre las dificultades surgidas a raíz de unas sublevaciones que tienen lugar en Hungría ${ }^{19}$.

En junio de 1605, San Clemente advierte sobre la situación del Imperio respecto a las invasiones otomanas, las persecuciones de los católicos por los herejes, así como también contra los jesuitas ${ }^{20}$.

Otro ejemplo lo encontramos en una carta fechada el 2 de febrero de 1605 , donde San Clemente da las gracias al rey de España por las tropas españolas que ha enviado, las cuales, nada más llegar, suprimieron la sublevación del líder Bocskai en Possonia (los húngaros, con el apoyo de los turcos, se habían sublevado entre 1604 y1606 bajo la dirección del transilvano István Bocskai ${ }^{21}$ )

El 23 de septiembre de1605, don Guillén escribe una carta sobre la posible firma de una paz entre Hungría y el emperador, y sobre la paz que se va afirmar con los turcos. Además, menciona los problemas entre Matías y Rodolfo II $^{22}$.

San clemente tuvo una especial vinculación con la parroquia Santo Tomás, sita en la Ciudad Pequeña de Praga - Malá Strana -. La iglesia de Santo Tomás se ha hecho acreedora durante su historia del apodo de "iglesia

17 Toda la serie documental (unos 516 legajos) descrita en el Catálogo II, Secretaría de Estado del Archivo General de Simancas, por Julián PAZ, Capitulaciones con la Casa de Austria y negociaciones de Alemania, Sajonia, Polonia, Prusia y Hamburgo. 1493-1796, $2^{a}$ ed., Consejo Superior de Investigaciones Científicas, Madrid, 1942.

${ }^{18}$ Guillén de San Clemente a Felipe III, Praha, 7 de febrero de 1605, AGS, Sección de Estado, leg. 708.

${ }^{19}$ Ibidem. Guillén de San Clemente a Felipe III, Praha, 6 de mayo de 1605.

${ }^{20}$ Ibidem. Guillén de San Clemente a Felipe III, Praha, junio de 1605.

${ }^{21}$ Ibidem. Guillén de San Clemente a Felipe III, Praha, 2 de febrero de 1605.

${ }^{22}$ Ibidem. Guillén de San Clemente a Felipe III, Praha, 23 de septiembre de 1605. 
de los españoles". Comenzó a ser llamada así durante el reinado de Felipe II e imperio de Rodolfo II. Dentro de la iglesia, frente a la entrada principal del recinto, se encuentra una lápida que señala entrada a la cripta donde está el sepulcro del embajador. San Clemente hizo construir la cripta en 1597 para enterrar a los españoles residentes en Praga, que muriesen sin medios para costearse un entierro. En realidad, don Guillén no quiso edificar su propio túmulo, sino hacer una obra benéfica en favor de sus paisanos, sin embargo, fue enterrado aquí sin haberlo esperado él mismo. En 1608, ya durante el reinado de Felipe III y encontrándose el embajador gravemente enfermo, pidió insistentemente ser relevado de su cargo a fin de poder morir y ser enterrado en España. Sin embargo, falleció sin poder cumplir su sueño y sus restos fueron enterrados en la cripta que él mismo hizo construir ${ }^{23}$. Más tarde, fue exhumado y trasladado a un monasterio dominicano en Barcelona. Su lápida presenta la estrella heráldica de David, aludiendo con ello a su origen converso.

Este es el epitafio latino que reza en su losa:

"Salve calcator huius marmoris

don Guillielmus de Sto Clemente

Regis Catholici in Germania Legatus

Eisudem Regis subditis

In spulturam perpetuam

Hoc conditorium exstruxit

Anno Christi MDXCVII.

Ave Maria, ${ }^{24}$.

Es decir: "Salve visitante de este monumento - Don Guillermo de San Clemente - legado en Germania del Rey Católico - construyo esta cripta como sepultura perpetua - para los súbditos del mismo Rey - en el año 1597 después de Cristo. - Ave María".

Se sabe que el embajador español favoreció repetidamente el templo de Santo Tomás. En la sacristía de la iglesia, como monumento funerario, San Clemente donó un cuadro representando una crucifixión de Cristo (que originalmente formaba parte del cenotafio del embajador español), acompañada de Santa Catalina y del propio don Guillén.

La inscripción al pie del cuadro apunta así:

D.O.M. (Al Señor Óptimo y Mayor)

Don Guillelmus de S. Clemente, caballero de la Orden de Santiago, embajador de su católica majestad Felipe III ante el emperador Rodolfo II hizo colocar aquí este monumento en el año del Señor de 1608.

${ }^{23}$ Ibidem. Guillén de San Clemente a Felipe III, Praha, 1608.

${ }^{24}$ CHUBODA, op. cit., 180. 
El embajador español murió a los 61 años en la ciudad de Praga. Según 25 dictámenes de algunos de los mejores médicos de la época, su enfermedad fue debida al reuma, que acabó produciéndole parálisis; además padecía de gota por el elevado consumo de carne de caza, algo característico de las clases más pudientes de la época.

En la Biblioteca premonstratense de Strahov en Praga, pueden encontrarse valiosos manuscritos e impresos antiguos en habla castellana. Algunos de los más antiguos aparecen dentro de una colección de 33 estudios médicos escritos en latín llamados "concilia diversoorum medicorum circanervorum debilitatem", aportados por el propio Guillén de San Clemente. Dentro de estos estudios encontramos diversas páginas en idioma español (189-196, 197-207, 211-222). Entre estas páginas, la segunda y tercera parte (197-207, 211-222), son idénticas.

La primera parte (189-196), es un extracto del libro del médico de Felipe II, Juan Cornejo, que se ocupaba de las curas de gota. El segundo fragmento (197-207) hace referencia a la enfermedad del embajador Guillén de San Clemente y sus posibles causas, así como un análisis de la alimentación y de la dieta recomendada para el embajador ${ }^{25}$.

Don Guillén, ya bastante envejecido, sufría intensos ataques de gota mientras escribía a su rey: "Hay vías por las que Dios me llama a Montserrat..."26 Estos problemas de salud permitían al embajador que, durante las audiencias con el emperador Rodolfo II, le fuese permitido postrarse en un sillón.

A finales de junio de 1608, San Clemente estaba tan enfermo que no podía mandar ninguna noticia a Madrid. El viejo embajador sabía que no le quedaban muchos días.

Durante toda la primavera, se había ocupado de que enviaran a Praga un sucesor, pidiendo insistentemente que le dejaran morir en territorio español. Sin embargo, las exigencias de la política le retuvieron allí más tiempo. En Madrid querían tener un diplomático con experiencia en unos momentos tan importantes como el conflicto sucesorio entre los hermanos Rodolfo y Matías. En la última carta que recibió el embajador, le pedían desde Madrid que se quedara hasta otoño de 1608 con las siguientes palabras, "hay que poner una firma a la obra."

Don Guillen de San Clemente murió el 3 de septiembre de 1608, 2 días después de la llegada de su sucesor don Baltasar de Zúñiga. A su muerte asistieron numerosas personalidades la época, entre las que figuraba su sobrino Baltasar de Marradas ${ }^{27}$.

Hay una carta muy interesante fechada el 19 de septiembre de 1608 con la firma del archiduque Alberto de Austria, hijo del emperador Maximiliano II,

25 Simona BINKOVA, Los materiales hispánicos y lusitanos en la biblioteca de Strahov, Biblioteca de Strahov, Praga, 1986, 96.

${ }^{26}$ CHUDOBA, op. cit., 157.

${ }^{27}$ Ibidem, 191. 
al Duque de Lerma, recomendando a Pedro Montañana, Secretario del difunto embajador en Praga. En esta carta se hace referencia a cómo Montañana, tras la muerte del embajador pasa a España a dar cuenta de las cosas ocurridas en dicha embajada, para que el rey Felipe III le haga alguna merced en consideración a sus servicios ${ }^{28}$.

También relacionado con la enfermedad, muerte y entierro de D. Guillén de San Clemente encontramos unos manuscritos muy interesantes en el Catálogo general de manuscritos de la Real Academia de la Historia (19101912) recogido por Antonio Rodríguez Villa ${ }^{29}$.

Dentro de esta referencia podemos encontrar una certificación firmada y sellada por el embajador Guillén de San Clemente, donde relata los especiales servicios prestados por parte de su secretario personal don Pedro Montañana. El documento está fechado a 6 de agosto de $1608^{30}$. En otro manuscrito fechado a 15 de septiembre de 1608 , observamos una referencia a la licencia temporal concedida por don Pedro de Enríquez y Acevedo, Conde de Fuentes y Capitán General y Gobernador del Estado de Milán a don Pedro Montañana, para que pase a Madrid ${ }^{31}$. Finalmente, dentro de este grupo de documentos, encontramos una carta del Rey Felipe III a Pedro Montañana, expresándole que se tiene por muy servido, en cuanto ha cumplido las órdenes de don Baltasar de Zúñiga (dadas en Madrid a 2 de abril de 1611), y del rey ${ }^{32}$.

${ }^{28}$ Se puede ver el original de la carta completa con la firma del Archiduque en, Real Academia de la Historia, Colección Salazar y Castro, A-63, f. 147. Está publicado además en la Colección de Documentos Inéditos para la Historia de España, tomo XLIII, 126.

29 Antonio RODRÍGUEZ VILLA, Catálogo general de manuscritos de la Real Academia de la Historia (1910-1912). Aragón. Colección Nasarre.10-10-6 (Ant.) 118-7-1428 11-1-1-7946, 6.

30 “[...] que Pedro Montañana es digno de qualquier laude y de que el Rey mi $S^{r}$ la haga muchas como tan ynteresando en estas mat. ${ }^{a s}$ por sangre y deuoción y premie demas de este otros muchos seruy. ${ }^{o s}$ que he recibido en diez años que a que me sirue

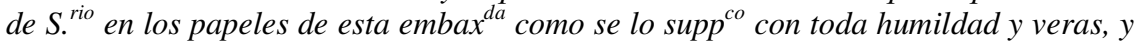
a los señores sus ministros que le ayuden para ello y le honren pues lo merece y en fee de la verdad hize la parte firmada de mi mano y sellada con el sello de mis armas en Praga a seis de agosto de mil seiscientos y ocho."

31 "Haviendonos representado $P^{o}$ Montañana $S^{\text {rio }}$ de los quatro Comis arios extraordinarios de muestras de esta estado que por la muerte de Don Guillen de $S^{\text {to }}$ Clemente embax de Alemania de quien hera $S^{\text {rio }}$ tiene necesidad de yr a la corte a dar quenta a su Mag de negocios tocantes a esta embaxada y para daros licencia para ello por el tiempo que fuese mia voluntad en cuya consideracion hemos tenido por bien de concedersela por el de seis meses que an de correr desde el dia de la fecha desta en adelante. Por tando ordenamos y mandamos a todos los ministros de su Mag ${ }^{d}$ sujetos a nuestra jurisdiçion y a los que no lo son pedimos y encargamos no le pongan impedimento alguno en el viaje."

32 "Pedro de Montañana mi criado, queda entendido por una carta de los 10 del pasado, como aviendo ydo a servir con licencia mía cerca de la persona del 
No podemos concluir esta monografía sobre la figura de don Guillén San Clemente, sin hacer una breve referencia a su biblioteca particular. Si San Clemente había vivido en Praga durante casi 30 años, podemos suponer que poseía una interesante colección de libros ${ }^{33}$. Sin embargo, se trata tan sólo de especulaciones, ya que, salvo excepciones, como algunas donaciones hechas a los jesuitas, no sabemos nada concreto sobre la existencia de su biblioteca. Tampoco se ha encontrado pruebas de que donara sus libros a la Iglesia de Santo Tomas de Mala Strana. Se puede suponer que quizás fueron heredados por sus familiares o su biblioteca podría haber sido transportada fuera de Bohemia, o posiblemente llegaron a ser una parte de colecciones de libros que hoy ya no existen.

Sabemos que el embajador apoyaba a los jesuitas no solo política e ideológicamente, sino también en sus intereses económicos. A finales del siglo XVI les dedicó la obra de Alfonso de Madrigal Tostado de Ribera, "Opera Abulensis". Alfonso de Madrigal fue Obispo de Ávila durante la primera mitad del siglo XV, así como un consumado autor de la época. Solía escribir bajo el pseudónimo "Juan de Torquemada" - tío del Inquisidor General.

En la Biblioteca Nacional de Praga se encontró otra donación de San Clemente a los jesuitas hecha en 1586 llamada, "Discussionum peripateticarum tomi IV', del filosofo italiano Frandesco Patrizziho. Finalmente hay que señalar, que un libro de viajes conservado en la Biblioteca Nacional de Praga conocido como "Historia de las cosas de Etiopía" del siglo XVI, procede casi con seguridad de la Biblioteca personal de San Clemente.

La biblioteca de Strahov de Praga, contiene diversos libros que podrían pertenecer a la colección personal de San Clemente, lo que podría aclararnos nuevas informaciones sobre la figura de este excepcional personaje ${ }^{34}$.

Comendador mayor de Montesa en la jornada que hizo a Florencia os escribió el embaxador Don Baltasar de Zúñiga que fuese [desde allí] a Alemania porque era necesaria una persona para mi servicio por la esperiencia que tenéis de las cosas de por allá del tiempo que fuisteis Secretario del Embaxador don Guillén de San clemente difunto, y tengome por muy servido de que ayais cumplido lo que Don Baltasar os escribió y lo seré de que lo continuéis en lo que ahí se os ofreciere y el os ordenare con el cuydado que conviene y de vos se espera, de Madrid a 2 de abril de 1611."

${ }^{33}$ Kaspar OLDRICH, "Literatura española e Iberoamericana de los siglos XVI-XVIII conservada en los fondos históricos de las Bibliotecas Checoslovacas", in: Varia bibliographica: homenaje a José Simón Díaz. Edition Reichenberger, 1988, 397-400.

${ }^{34}$ Jaroslava KAŠPAROVÁ, "Příspěvek k působení španělských vyslanců Juana de Borja a Guilléna de San Clemente na dvoře Rudolfa II", in: Miscellanea, Praha, 15, 1998, 144-146. 